Supplement of Hydrol. Earth Syst. Sci., 18, 2679-2694, 2014

http://www.hydrol-earth-syst-sci.net/18/2679/2014/

doi:10.5194/hess-18-2679-2014-supplement

(C) Author(s) 2014. CC Attribution 3.0 License.

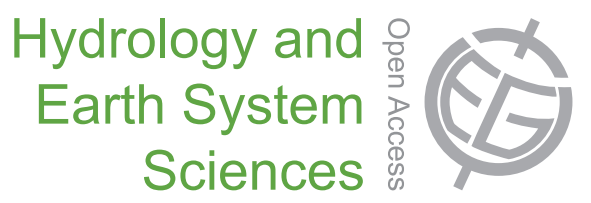

(c) (i)

Supplement of

\title{
Modelling runoff from a Himalayan debris-covered glacier
}

K. Fujita and A. Sakai

Correspondence to: K. Fujita (cozy@nagoya-u.jp) 
Supplementary Table S1. Details of ASTER data

\begin{tabular}{llll}
\hline Date & ASTER data ID & Location of image centre & Quality \\
\hline 25 Oct. 2004 & ASTL1A 0410250458240411040498 & $27.843802^{\circ} \mathrm{N}, 86.494104^{\circ} \mathrm{E}$ & Good \\
10 Nov. 2004 & ASTL1A 0411100458190411210131 & $27.811015^{\circ} \mathrm{N}, 86.722839^{\circ} \mathrm{E}$ & Good \\
28 May 2005* & ASTL1A 0505280504530505310448 & $28.151466^{\circ} \mathrm{N}, 86.603573^{\circ} \mathrm{E}$ & $\mathrm{Good}$ \\
28 May 2005* & ASTL1A 0505280505020505310449 & $27.620051^{\circ} \mathrm{N}, 86.463317^{\circ} \mathrm{E}$ & $\mathrm{Good}$ \\
29 Nov.2005 & ASTL1A 0511290458400512020077 & $27.804141^{\circ} \mathrm{N}, 86.773017^{\circ} \mathrm{E}$ & $\mathrm{Bad}$ \\
6 Dec. 2005 & ASTL1A 0512060504480512090573 & $27.646678^{\circ} \mathrm{N}, 86.289759^{\circ} \mathrm{E}$ & $\mathrm{Bad}$ \\
1 Feb. 2006 & ASTL1A 0602010458090602040117 & $27.820009^{\circ} \mathrm{N}, 86.663070^{\circ} \mathrm{E}$ & $\mathrm{Good}$ \\
19 Jan. 2007 & ASTL1A 0701190459340701220148 & $27.837430^{\circ} \mathrm{N}, 86.540530^{\circ} \mathrm{E}$ & $\mathrm{Bad}$ \\
23 Feb. 2008 & ASTL1A 0802230459310903220613 & $27.830978^{\circ} \mathrm{N}, 86.586113^{\circ} \mathrm{E}$ & $\mathrm{Bad}$ \\
\hline
\end{tabular}

*Two images are merged into one mosaic image. 


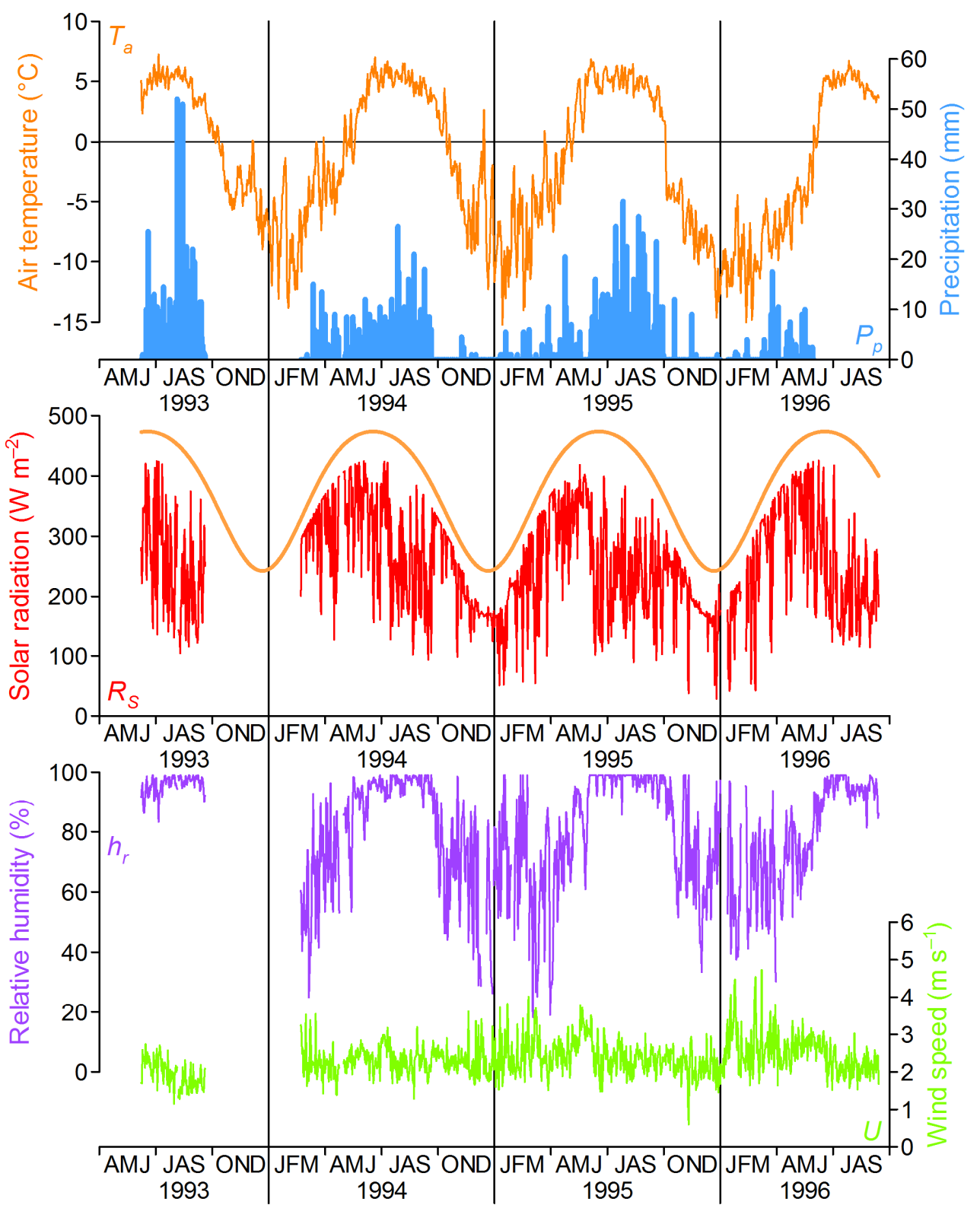

Figure S1. Meteorological variables observed at the outlet (the cross in Fig. 1a) of the Tsho Rolpa Glacial Lake-Trambau Glacier basin for the period 1993-1996. $T_{a}, P_{p}, R_{S}, h_{r}$ and $U$ denote air temperature, precipitation, solar radiation, relative humidity and wind speed, respectively. The smoothed line in the solar radiation plot denotes radiation calculated at the top of the atmosphere. 

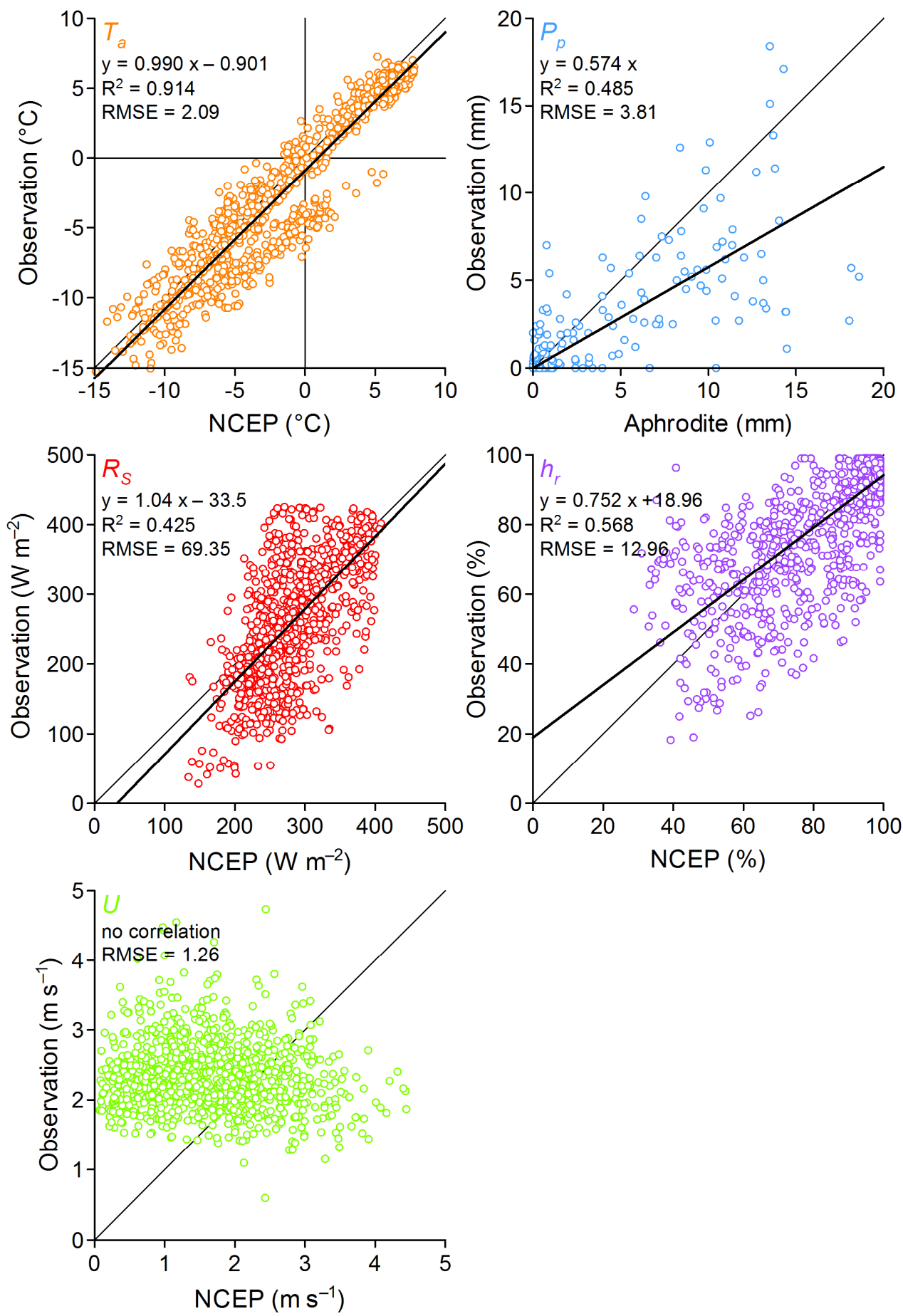

Figure S2. Comparisons between gridded and observational data at the outlet (the cross in Fig. 1a) of the Tsho Rolpa Glacial Lake-Trambau Glacier basin for the period 1993-1996. $T_{a}, P_{p}, R_{S}, h_{r}$ and $U$ denote air temperature, precipitation, solar radiation, relative humidity and wind speed, respectively. Pentad (5-day) data are compared for precipitation while the others are daily values. Thin and thick lines denote one-to-one and linear regression lines, respectively. The intercept for precipitation is set to zero. 